\title{
Inheritance of Prehaustorial Resistance to Puccinia graminis f. sp. avenae in Barley (Hordeum vulgare L.)
}

\author{
Peter M. Dracatos, ${ }^{1}$ Michael Ayliffe, ${ }^{2}$ Mehar S Khatkar, ${ }^{3}$ Tom Fetch, Jr., ${ }^{4}$ Davinder Singh, ${ }^{1}$ and Robert F. Park ${ }^{1}$ \\ ${ }^{1}$ The University of Sydney, Plant Breeding Institute Cobbitty, Private Bag 4011, Narellan, NSW, 2567, Australia; ${ }^{2} \mathrm{CSIRO}$ \\ Plant Industries, Box 1600, Clunies Ross Street, Acton, Canberra, Australia, 2601; ${ }^{3}$ ReproGen-Animal Bioscience Group, \\ Faculty of Veterinary Science, University of Sydney, Camden, NSW, Australia; ${ }^{4}$ Cereal Research Centre, Agriculture \& \\ Agri-Food Canada, Winnipeg, MB, Canada
}

Submitted 18 May 2014. Accepted 3 July 2014.

Rust pathogens within the genus Puccinia cause some of the most economically significant diseases of crops. Different formae speciales of $P$. graminis have co-evolved to mainly infect specific grass hosts; however, some genotypes of other closely related cereals can also be infected. This study investigated the inheritance of resistance to three diverse pathotypes of the oat stem rust pathogen ( $P$. graminis f. sp. avenae) in the 'Yerong' $\times$ 'Franklin' (Y/F) barley doubled haploid (DH) population, a host with which it is not normally associated. Both parents, 'Yerong' and 'Franklin', were immune to all $P$. graminis f. sp. avenae pathotypes; however. there was transgressive segregation within the Y/F population, in which infection types (IT) ranged from complete immunity to mesothetic susceptibility, suggesting the presence of heritable resistance. Both QTL and marker-trait association (MTA) analysis was performed on the Y/F population to map resistance loci in response to $P$. graminis f. sp. avenae. QTL on chromosome 1H ('Yerong' Rpga1 and Rpga2) were identified using all forms of analysis, while QTL detected on $5 \mathrm{H}$ ('Franklin' Rpga3 and Rpga4) and 7H (Rpga5) were only detected using MTA or composite interval mapping-single marker regression analysis respectively. Rpgal to Rpga5 were effective in response to all $P$. graminis f. sp. avenae pathotypes used in this study, suggesting resistance is not pathotype specific. Rpgal colocated to previously mapped QTL in the Y/F population for adult plant resistance to the barley leaf scald pathogen (Rhynchosporium secalis) on chromosome 1H. Histological evidence suggests that the resistance observed within parental and immune DH lines in the population was prehaustorial and caused by callose deposition within the walls of the mesophyll cells, preventing hyphal penetration.

Stem rust, caused by different formae speciales of Puccinia graminis, is the major disease of cereal crops and pastures, causing crop failure in severe cases. The high propensity for rapid changes in rust pathogen populations by either step-wise

Corresponding author: P. M. Dracatos;

E-mail: peter.dracatos@sydney.edu.au

* The $\boldsymbol{e}$-Xtra logo stands for "electronic extra" and indicates that three supplementary figures are published online.

(C) 2014 The American Phytopathological Society mutation (Wellings and McIntosh 1990), mitotic or meiotic recombination (Bartos et al. 1969; Park et al. 1999; Watson 1970 ) or by wind- or human- aided migration (Hovmøller et al. 2003; Watson and deSousa 1982; Wellings et al. 1987) is of particular concern to cereal breeders, due to the potential for rapid breakdown of resistance. The emergence of $P$. graminis f. sp. tritici race TTKSK (" $U g 99$ ") provided a graphic example of how rust pathogens can acquire virulence for resistance genes, such as $S r 31$, that have been deployed widely and remained effective for over 50 years (Pretorius et al. 2000; Singh et al. 2008). Furthermore, in recent years, the oat stem rust pathogen $P$. graminis f. sp. avenae has evolved to acquire virulence for all known deployed resistance genes in cultivated oats and emphasizes the requirement for durable sources of resistance to $P$. graminis.

Understanding the genetic basis of the specificity of formae speciales of rust pathogens such as $P$. graminis may lead to new approaches to the genetic control of these diseases. $P$. graminis f. sp. tritici mostly infects wheat, but it also infects barley and cereal rye, while the rye stem rust pathogen $P$. graminis $\mathrm{f}$. $\mathrm{sp}$. secali can infect barley but only very few wheat genotypes. A very early study reported that barley was susceptible to infection by all formae speciales of $P$. graminis (Grove 1913). A later study, describing the pathogenicity of progeny from interhybridizing $P$. graminis f. sp. tritici and $P$. graminis f. sp. secali, led to the conclusion that barley may, in fact, be the original host of $P$. graminis and that, over evolutionary time, $P$. graminis evolved to parasitize other grass and cereal species (Green 1971). P. graminis $\mathrm{f}$. sp. avenae is not closely related to other formae speciales of $P$. graminis, based on morphology and inability to cross hybridize, and it is specialized mainly to Avena spp. and other grasses within the Pooideae subtribe. Interestingly, recent studies demonstrated that formae speciales of $P$. graminis, such as $P$. graminis f. sp. avenae and $P$. graminis f. sp. lolii that have evolved to mainly infect species within the Pooideae subtribe, show higher levels of compatibility than observed for P. graminis f. sp. tritici on Brachypodium distachyon. This is somewhat surprising, given that $B$. distachyon is understood to be more closely related to the Triticeae (wheat and barley) than to oat or Lolium grasses in the Pooideae subtribe (Ayliffe et al. 2013; Figueroa et al. 2013). The interactions reported above have been described as near nonhost, are likely to be the most common form of resistance in plants, and could potentially be more durable (Niks and Marcel 2009).

The mechanisms by which adapted microbial pathogens infect host species are well understood relative to the interaction 
between plants and nonadapted pathogens (Collins et al. 2007; Dangl and Jones 2006). Previous studies suggest that there are distinct layers of resistance in response to nonadapted pathogens, which include leaf surface topology and chemical environment, penetration resistance at the cell wall, and downstream resistance pathways (salicylic acid and reactive oxygen species) (Fan and Doerner 2012; Schulze-Lefert and Pangstruga 2011). Recent studies on nonhost resistance in rice demonstrated that several cereal rust pathogens could colonize mesophyll cells with haustoria and that resistance was largely due to the production of callose and reactive oxygen species (Ayliffe et al. 2011; Yang et al. 2013). Numerous studies have also reported on the simple inheritance of near-nonhost resistance (Ayliffe et al. 2013; Jafary et al. 2008; Niu et al. 2013; Pahalawatta and Chen 2005; Rodrigues et al. 2004; Sui et al. 2010). In barley, Jafary and co-workers (2008) recently mapped a resistance gene for hypersensitive resistance to the nonadapted rust pathogens $P$. hordei-secalini and $P$. hordei-murini on the centromeric region of chromosome $1 \mathrm{H}$ in the Oregon $\times$ Wolfe mapping population. In contrast, inheritance of near-nonhost resistance to heterologous rust species in different barley mapping populations was quite a complex trait characterized by multiple minor QTL (Jafary et al. 2008; Niks and Marcel 2009).

The extent to which resistance genes to nonadapted pathogens are shared between some barley cultivars remains unclear and warrants further investigation. However, if resistance genes effective against nonadapted pathogens have not been selected for from a historical breeding perspective, then it is likely that there may be large overlap between such genes. Further tests of allelism are required to confirm the presence of shared resistance genes effective against multiple pathotypes of nonadapted rust pathogens. Allelism tests were previously performed on two resistant barley cultivars and no segregation was observed, suggesting the presence of the same gene for resistance in barley to $P$. graminis $\mathrm{f}$. sp. avenae, which differed from the resistance gene effective against $P$. graminis f. $\mathrm{sp}$. tritici (Martens et al. 1983). This study assessed the genetic basis and inheritance of near-nonhost resistance to diverse $P$. graminis f. sp. avenae pathotypes from Australia and Canada in the 'Yerong' $\times$ 'Franklin' $(\mathrm{Y} / \mathrm{F})$ barley doubled haploid $(\mathrm{DH})$ population, using both trait dissection analysis and histology of infection structures.

\section{RESULTS}

\section{Genetic analysis of resistance}

\section{to $P$. graminis f. sp. avenae in barley.}

Both parental genotypes ('Yerong' and 'Franklin' barley) were immune, based on low infection types (IT) of 0 ; and $0 ;-$, respectively, and the susceptible oat control 'Swan' displayed a high IT of $3+$, when inoculated with three diverse $P$. graminis f. sp. avenae pathotypes in separate experiments (Fig. 1). Transgressive segregation was observed in the progeny of the $\mathrm{Y} / \mathrm{F}$ population based on IT ranging from immune $(0 ;-$ to $0 ;)$ to partially susceptible (ranging from ;;+X to $\mathrm{X}+$ ) (Fig. 1). Partial susceptibility to $P$. graminis f. sp. avenae in barley, in all cases, was characterized by mesothetic IT. Chi-squared $\left(\chi_{2}\right)$ analysis was performed to determine the goodness of fit of observed segregation with expected genetic ratios for a $\mathrm{DH}$ population (Table 1). Binary phenotypic assessment determined that the segregation pattern of the $\mathrm{Y} / \mathrm{F}$ population showed a good fit to a 5:3 ratio for all $P$. graminis f. sp. avenae pathotypes tested and suggests the presence of two complementary genes and a single independently assorting gene for resistance (Table 1). Quantitative analysis also demonstrated that the continuous quantitative variation observed for resistance to the different $P$. graminis $\mathrm{f}$. sp. avenae pathotypes indicates polygenic inheritance of resistance in the $\mathrm{Y} / \mathrm{F}$ population in response to all pathotypes tested (Fig. 2).

\section{Genetic map construction and QTL mapping of resistance to $P$. graminis $\mathrm{f}$. sp. avenae in barley.}

The Y/F DH population (177 DH lines) was previously genotyped with a set of 1,050 diversity arrays technology (DArT) assays from a Pst $\mathrm{I} / B$ st $\mathrm{NI}$ representation ('bPb'markers), 386 of which were assigned to the genetic map spanning $1,035 \mathrm{cM}$ (Jaccoud et al. 2001). Several other marker types were also genotyped on this population, singly or in combination, i.e., simple sequence repeat (SSR), restriction fragment length

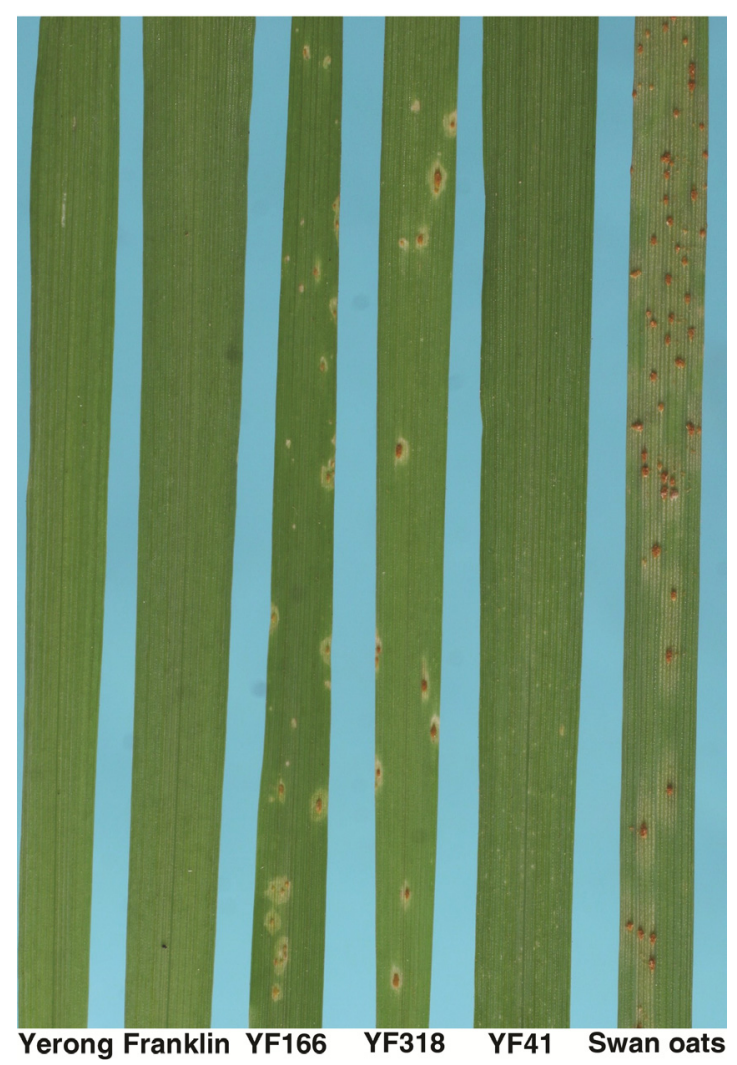

Fig. 1. Seedling leaves of the infection types of parental genotypes and individual lines from the doubled haploid mapping population: 'Yerong', 'Franklin', YF166, YF41, YF318, and the oat susceptible host genotype 'Swan' infected with the Puccinia graminis f. sp. avenae pathotype 41 $+P g 9, P g 13$, and $P g A$.

Table 1. Seedling plant resistance response of barley lines derived from the 'Yerong' $\times$ 'Franklin' doubled haploid population to three diverse Puccinia graminis f. sp. avenae pathotypes

\begin{tabular}{|c|c|c|c|c|c|c|c|}
\hline Pathotype & Virulence/avirulence & Res (R) & Sus (S) & $\mathrm{X}^{2}$ (R:S) & Genetic ratio & $\mathbf{P}$ & Genes predicted $^{\mathrm{a}}$ \\
\hline NA1 & $6,15 / 1,2,3,4,8,9,10,12,13,16$ & 81 & 53 & 0.823 & $5: 3$ & 0.40 & 3 \\
\hline NA67 & $1,2,3,4,8,9,13,15 / 6,10,12,16$ & 85 & 49 & 0.624 & $5: 3$ & 0.45 & 3 \\
\hline $41+P g 9, P g 13, P g A$ & $1,2,3,4,5,6,7,8+P g 9+P g 13+P g A$ & 79 & 57 & 0.288 & $5: 3$ & 0.60 & 3 \\
\hline
\end{tabular}

${ }^{a}$ Chi squared analysis involved testing the genetic model of the presence of two complementary genes and an independently assorting gene in a double haploid population (5:3 segregation ratio). 
polymorphism, or sequence-tagged site (STS) markers, and 22 of these were assigned to map positions (Wenzl et al. 2006; Xue et al. 2010). Single marker regression (SMR) analysis was performed between phenotypic scores and marker genotypic data for each seedling test using the three $P$. graminis $\mathrm{f}$. $\mathrm{sp}$. avenae pathotypes listed in Table 1 and, in all cases, significantly associated $(P<0.001)$ marker loci were exclusively located in chromosomal regions containing QTL. In total, seven QTL were detected using QTL Cartographer in three genomic regions. Rpgal ( $R$ [=resistance] pga $[P$. graminis $\mathrm{f} . \mathrm{sp}$. avenae $])$ and Rpga 2 were both identified on $1 \mathrm{H}$ in addition to a single region on 7H (Rpga5), and all QTL exceeded the genome-wide threshold of 2.5 , using composite interval mapping (CIM) following 1,000 permutations (Fig. 3; Table 2). Rpgal was located in close proximity to the $b P b-9337$ DArT marker and, in all cases, represented QTL of large magnitude accounting for between 22 to $26 \%$ of the phenotypic variation $\left(\mathrm{V}_{\mathrm{p}}\right)$. Rpga5 was identified in response to a single Canadian and Australian pathotype and was closely linked $(<1 \mathrm{cM})$ to the SSR marker Ebmac0603, accounting for 16 to $22 \% \mathrm{~V}_{\mathrm{p}}$, using only CIM and SMR (Fig. 3; Table 2).

\section{Marker-trait association (MTA) analysis in the $\mathrm{Y} / \mathrm{F}$ population.}

MTA analysis was performed using 8,564 DArTseq markers and phenotypic data (binary and quantitative) derived from independent seedling tests with three $P$. graminis $\mathrm{f}$. sp. avenae pathotypes. MTA analysis identified four resistance loci (Rpgal to Rpga4) in response to all three $P$. graminis f. $\mathrm{sp}$. avenae pathotypes tested (Fig. 4; Table 3; Supplementary Figs. 1 and 2). Additional QTL of very minor effect were identified using quan-

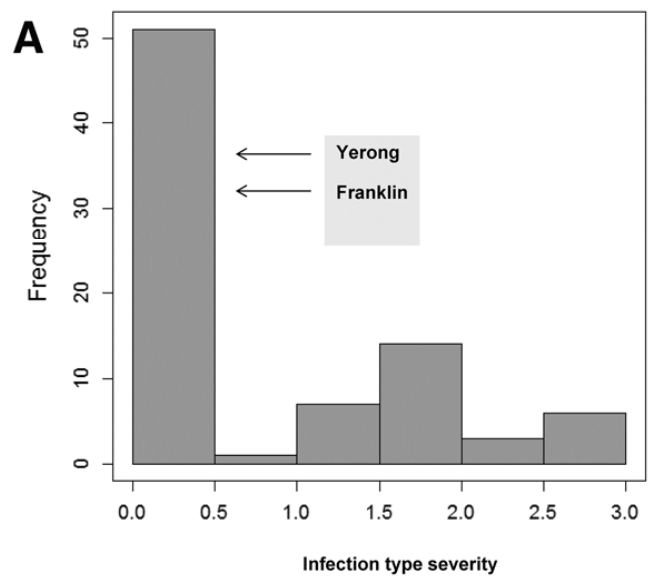

titative data; however, all were highly variable across datasets (Supplementary Fig. 3). MTA analysis demonstrated that Rpgal and Rpga2 (contributed by 'Yerong') were both located on chromosome $1 \mathrm{H}$ and were two distinct QTL separated by approximately $20 \mathrm{cM}$ (Table 3; Fig. 4). MTA data was also supported by CIM and SMR analysis using QTL Cartographer, which identified two closely linked markers for Rpgal and Rpga2 at 30 $\mathrm{cM}(b P b-9337)$ and $68 \mathrm{cM}(b P b-8187)$, respectively (Fig. 3). Both MTA and CIM analysis indicated that Rpga2 represented a minor QTL in comparison with Rpgal, accounting for 10 to $12 \%$ of $\mathrm{V}_{\mathrm{p}}$, and in all instances, significantly associated markers to Rpga2 had higher $P$ values relative to those markers closely linked to Rpgal (Tables 2 and 3). Rpga3 and Rpga4, contributed by the 'Franklin' parent, represented two distinct QTL identified on 5HS (31 cM) and 5HL (47 cM), respectively, in response to all pathotypes. Both Rpga3 and Rpga4 were identified only using MTA analysis (both binary and quantitative data) and were not detected using SMR or CIM analysis (Fig. 4; Table 3). Rpga3 was weakly associated with resistance to $P$. graminis $\mathrm{f}$. sp. avenae pathotype $41+P g 9, P g 13, P g A$ compared with both Canadian isolates tested (Table 3). Conversely, Rpga4 was more strongly associated with resistance in response to $P$. graminis $\mathrm{f}$. sp. avenae pathotype $41+P g 9, P g 13, P g A$ compared with Rpga1, Rpga2, and especially, Rpga3 (Table 3).

\section{Co-location of QTL for seedling resistance to $P$. graminis f. sp. avenae and QTL for adult plant resistance (APR)} to multiple diseases in the $\mathrm{Y} / \mathrm{F}$ population.

Rpgal co-located to previously identified QTL for APR to the barley leaf scald pathogen (Rhynchosporium secalis)
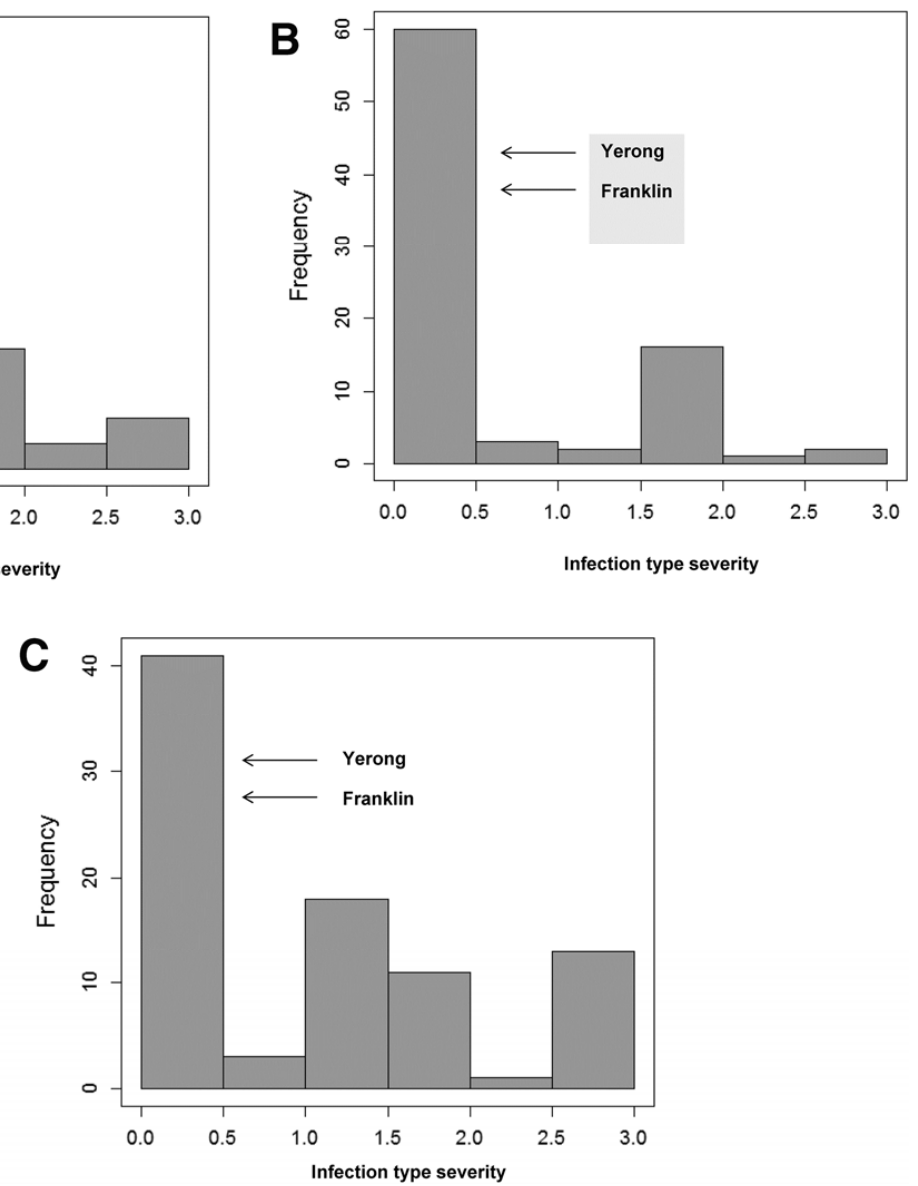

Fig. 2. Frequency distribution of phenotypes for resistance, measured as severity of infection type ( 0 to 4 scale), to the three Puccinia graminis f. sp. avenae pathotypes A, NA1, B, NA67, and $\mathbf{C}, 41+P g 9, P g 13, P g A$ in the Y/F mapping population. Values of the two parental lines are shown by arrows. 
(QSc.YerFr.1H) on $1 \mathrm{H}$ in a Y/F population (Li and Zhou 2011) (Fig 5A). QSc.YerFr.1H mapped within 1 to $2 \mathrm{cM}$ of Rpgal (SMR and CIM), and both QTL shared the same most closely linked marker $b P b-9337$ (Fig 5A). Comparative mapping analysis was performed using bridging DArT, SSR, amplification fragment length polymorphism, and STS markers from the Steptoe $\times$ Morex genetic map and previously identified QTL for APR to Blumeria graminis f. sp. hordei to identify possible co-location to known candidate genes involved in resistance (Aghnoum et al. 2010; Wenzl et al 2006). Putative co-locations were identified on chromosome $1 \mathrm{H}$, in which both Rpgal and

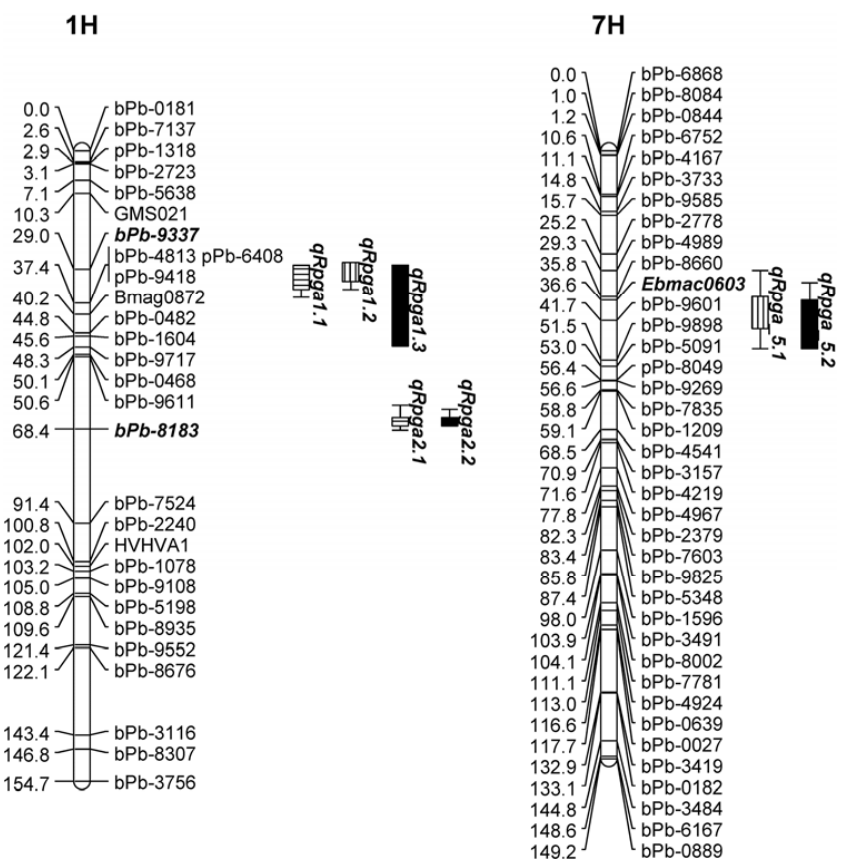

Fig. 3. Location of quantitative trait loci (QTL) for oat stem rust resistance measured at the seedling stage for the 'Yerong' $\times$ 'Franklin' doubled haploid mapping population. The genetic map comprised a total of 408 markers (386 DArTs and 22 other marker types, including one or more simple sequence repeat, restriction fragment length polymorphism, or sequencetagged site markers) (Wenzl et al. 2006; Xue et al. 2010). Markers were selected based on average intervals of $3 \mathrm{cM}$ to provide even genome coverage. Composite interval mapping (CIM) methods were used to identify and confirm the presence of QTL using QTL Cartographer 2.5 software (Basten et al. 1994). The maximum log of odds (LOD) score of association between the genotype and trait data was calculated, and QTL location predictions were accepted for LOD values greater than a threshold value of 2.5. Permutation analysis (1,000 iterations) was used to establish an experiment-wise significance value at the 0.05 confidence level, defined as a minimum LOD threshold for each trait in CIM (Churchill and Deorge 1994; Doerge and Churchill 1996). Bars and lines represent 1 and 2 LOD drops from maximum LOD value, respectively. Solid black, horizontal, and vertical striped boxes represent infection using three separate Puccinia graminis f. sp. avenae pathotypes: i) $41+P g 9, P g 13$, and $P g A$, ii) NA1, and iii) NA67, respectively.
Rpga2 were identified in the same genomic regions as $R b g q 5$ (Mlnn) and Rbgq6 (Rorl), respectively (Aghnoum et al. 2010) (Fig. 5B).

Resistance to $P$. graminis f. sp. avenae is prehaustorial.

Microscopic analyses were performed on both parental and Y/F DH lines (YF41, YF166, and YF318) that were selected based on visual infection type as shown in Figure 1. Barley leaves infected with $P$. graminis f. sp. avenae were sampled at $2,5,10$, and 18 days postinoculation (dpi) to compare disease development with the oat host control genotype 'Swan'. Macroscopically obvious rust growth was observed on YF166 and YF318, whereas the two parental lines and YF41 showed apparent immunity (Fig. 1). There was an obvious increase in latency period of $P$. graminis $\mathrm{f}$. sp. avenae infection in barley lines YF318 and YF166 compared with the susceptible 'Swan' oat control. At all stages $(2,5,10$, and $18 \mathrm{dpi})$, P. graminis f. sp. avenae infection in oat was more advanced than any barley line, with an even spread of colonies, and complete hyphal colonization of oat occurred between 5 to 10 dpi (Fig. 6). The most susceptible barley line YF318 was significantly colonized by $P$. graminis f. sp. avenae, with some of the colonies producing uredinia, and had a mesothetic IT characteristic of $P$. graminis infection on barley.

Microscopic examination of parental lines ('Yerong' and 'Franklin') and immune DH line YF41 at both 2 and 5 dpi identified numerous rust infection sites and demonstrated that $P$. graminis f. sp. avenae was able to germinate, find stomata, produce appressoria, substomatal vesicles. and short infection hyphae (Fig. 6). When assessed up to $18 \mathrm{dpi}$, infection structures in both the parental and immune DH line (YF41) did not develop further on both parental and immune lines, whereas, in susceptible lines and the control, disease development increased (Fig. 6C to H, M, and O). On each parental line, no P. graminis f. sp. avenae infection sites were observed that successfully penetrated plant cell walls to produce haustoria (Fig 6E and $\mathrm{H})$. At each timepoint, all infection hyphae observed in immune lines appeared to terminate at the surface of plant mesophyll cells and plant cell-wall appositions were often apparent at attempted penetration sites (Hukelhoven 2007) (Fig. 6E). In some experiments, these cell appositions were associated with an accumulation of autofluorescent material at sites of infection hyphae contact (Fig. 6I toL). These data demonstrate that the $P$. graminis f. sp. avenae resistance conferred by each parental line is based upon an active prehaustorial-based defense mechanism.

\section{DISCUSSION}

The ability of a Puccinia species to colonize nonhost species is initially dependent on the ability of germinating urediniospores to find stomata and, then, to produce the infection structures necessary to facilitate biotrophy. Previous research deter-

Table 2. Single marker regression (SMR) and composite interval mapping (CIM) results of the quantitative trait loci (QTL) analysis for oat stem rust resistance traits in the 'Yerong' $\times$ 'Franklin' doubled haploid barley mapping population using QTL Cartographer

\begin{tabular}{|c|c|c|c|c|c|c|c|}
\hline Pathotype & QTL identifier & Chromosome & $\begin{array}{c}\text { SMR } \\
P<0.01(\mathrm{cM})\end{array}$ & $\begin{array}{c}\text { Most closely } \\
\text { linked marker }\end{array}$ & $\begin{array}{c}\text { CIM } \\
\text { maximum LOD }{ }^{\text {a }} \text { score }\end{array}$ & Position (cM) & $\mathrm{V}_{\mathrm{p}}(\%)$ \\
\hline \multirow[t]{2}{*}{ NA1 } & qRpgal.1 & $1 \mathrm{H}$ & 29.02 to 68.42 & $b P b-9337$ & 8.65 & 30.5 & 22.02 \\
\hline & qRga2.1 & $1 \mathrm{H}$ & $\mathrm{ns}$ & $b P b-8183$ & 4.07 & 68.02 & 10.02 \\
\hline \multirow[t]{2}{*}{ NA67 } & qRgal.2 & $1 \mathrm{H}$ & 3.09 to 50.63 & $b P b-9337$ & 6.71 & 27.29 & 26 \\
\hline & qRga5.1 & $7 \mathrm{H}$ & 29.02 to 68.42 & Ebmac0603 & 6.36 & 36.62 & 15.8 \\
\hline \multirow[t]{3}{*}{$41+P g 9+P g 13$} & qRgal.3 & $1 \mathrm{H}$ & 29.02 to 68.42 & $b P b-9337$ & 6.60 & 27.29 & 24 \\
\hline & $q \operatorname{Rga} 2.2$ & $1 \mathrm{H}$ & ns & $b P b-8183$ & 2.58 & 69.43 & 12.22 \\
\hline & qRga5.2 & $7 \mathrm{H}$ & 36.60 to 77.77 & Ebmac0603 & 4.62 & 36.62 & 22 \\
\hline
\end{tabular}

${ }^{\mathrm{a}} \mathrm{LOD}=\log$ of odds. 
mined that specific chemicals and leaf surface topography may initially determine whether or not a pathogen can infect a given plant species or genotype (Allen et al. 1990; Collins et al. 2007; Grambow 1977). In this study, not only did nearly all $P$. graminis f. sp. avenae germlings successfully locate stomata, they also produced appressoria, substomatal vesicles, and infection hyphae across all barley lines tested. These results suggest that the surface topography and chemical properties of both barley and oat leaves are conducive to the development of both prepenetration and internal infection structures of $P$. graminis f. sp. avenae. P. graminis f. sp. avenae, however, was not able to produce haustoria and, therefore, colonize the mesophyll cells of either of the barley parental genotypes 'Yerong' or 'Franklin' or the immune DH line YF41 due to the presence of heritable resistance. Transgressive segregation was observed in which a proportion of $\mathrm{DH}$ lines were more susceptible than either parent, due to the absence of resistance derived from one or more parents. The most susceptible DH lines that lacked resistance from both parental sources exhibited mesothetic IT, characteristic of $P$. graminis infection on barley. Martens and coworkers (1983) have previously demonstrated incomplete susceptibility and observed mesothetic IT in barley to four diverse $P$. graminis f. sp. avenae pathotypes.

Previous studies suggest that the inheritance of near-nonhost resistance may be simply inherited and, in some instances, can be complex, involving many genes. Niu and co-workers (2013) designated a single dominant gene $(P c l)$ for resistance in wheat on chromosome 5D to the barley crown rust pathogen $P$. coronata f. sp. hordei. Pahalawatta and Chen (2005) and Sui and coworkers (2010) demonstrated that resistance in wheat to the barley stripe rust pathogen caused by $P$. striiformis f. sp. hordei and of barley to $P$. striiformis f. sp. tritici was conferred by a single dominant gene. Conversely, some studies in barley report on numerous overlapping QTL (minor gene and partial resistance mechanisms) in response to $P$. triticina and other diverse Puccinia spp. (Jafary et al. 2008). The current study reports, for the first time, on the inheritance and mapping of resistance loci in barley in response to $P$. graminis $\mathrm{f}$. $\mathrm{sp}$. avenae. The QTL mapping results identified three resistance loci: Rpgal $(1 \mathrm{H})$, Rpga2 $(1 \mathrm{H})$, and Rpga5 $(7 \mathrm{H})$ and correlated with the Chi-square analysis based on the genetic model for a 5:3 (three gene) ratio in a DH population. Rpgal and Rpga2, contributed by the 'Yerong' parent, were detected using all forms of analysis; however, in two instances, QTL analysis and MTA analysis gave different results. Rpga5 mapped on chromosome $7 \mathrm{H} \quad(<0.1 \mathrm{cM}$ away from the SSR marker EBmac0603) using both SMR and CIM but was not identified using MTA. Furthermore, Rpga3 and Rpg4 on chromosome $5 \mathrm{H}$, contributed by the 'Franklin' parent, was consistently detected using only MTA analysis. Variation in both the location and number of resistance loci identified between methods is likely to be a function of increased DArTseq marker density compared with the initial Y/F map build and potential sequence duplication between the telomeric regions of chromosome $5 \mathrm{H}$.
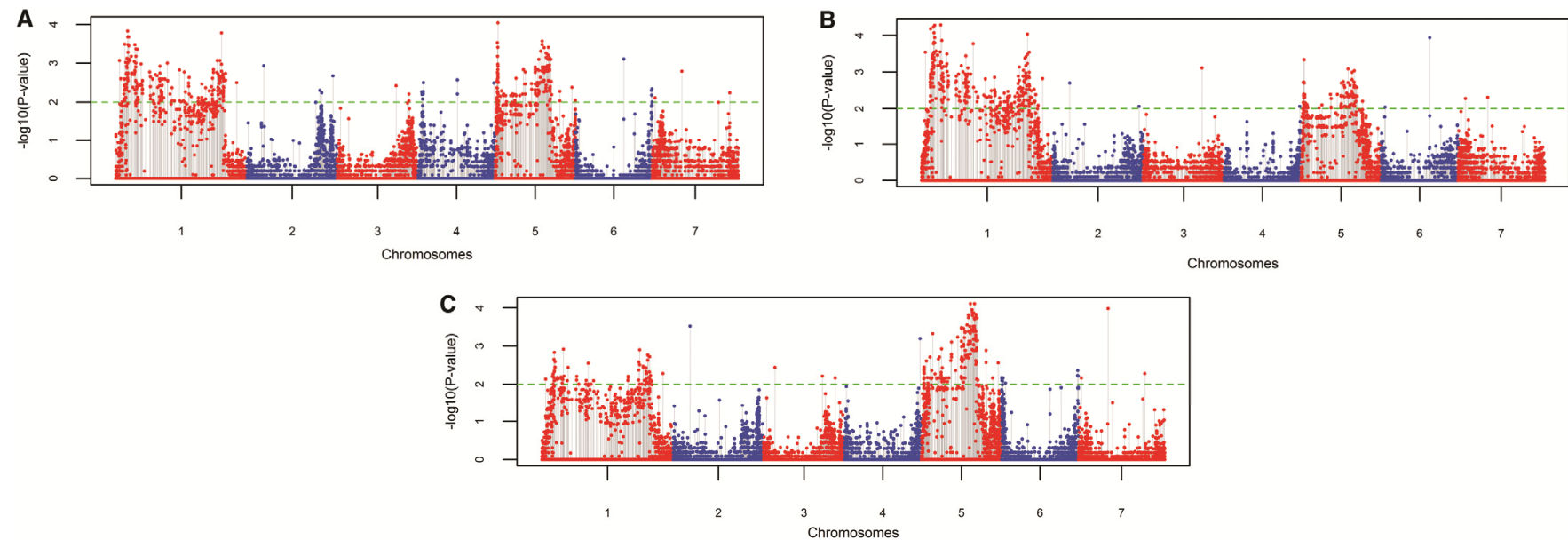

Fig. 4. A, Marker trait association analysis scans using Fisher's exact test for seedling resistance to Puccinia graminis f. sp. avenae pathotypes NA1, B, NA67, and $\mathbf{C}, 41+P g 9, P g 13, P g A$ (binary scoring data) in the 'Yerong' $\times$ 'Franklin' population using 8,564 DArTseq markers. The vertical axis represents $-\log 10(P)$ values of the $P$ value of the marker trait association. The peaks above minimum threshold of $2(P$ value $=0.03)$ can be considered significantly associated Blue and red were used to differentiate between chromosomes (1H and $7 \mathrm{H}$, respectively).

Table 3. Genome-wide association analysis showing the most significantly associated DArT markers with resistance to different Puccinia graminis f. sp. avenae pathotypes

\begin{tabular}{|c|c|c|c|c|c|c|c|}
\hline Pathotype & Marker name & $\begin{array}{c}\text { Genetic } \\
\text { position }(\mathrm{cM})\end{array}$ & Chromosome & $\begin{array}{l}\text { Position } \\
\text { (Mb) }\end{array}$ & $P$ value & $\begin{array}{c}\text { Resistant } \\
\text { parent }\end{array}$ & $\begin{array}{c}-\log 10 \\
P \text { value }\end{array}$ \\
\hline $41+P g 9, P g 13, P g A$ & $\begin{array}{l}\text { 3396786|F|0 } \\
3255793|\mathrm{~F}| 0-23: \mathrm{T}>\mathrm{G}-23: \mathrm{T}>\mathrm{G} \\
3260193|\mathrm{~F}| 0 \\
3270122|\mathrm{~F}| 0\end{array}$ & $\begin{array}{l}47.67 \\
47.13 \\
68.7 \\
30.87\end{array}$ & $\begin{array}{l}5 \mathrm{H} \\
1 \mathrm{H} \\
1 \mathrm{H} \\
5 \mathrm{H}\end{array}$ & $\begin{array}{l}3.48 \mathrm{e}+08 \\
75276680 \\
3.75 \mathrm{e}+08 \\
19657720\end{array}$ & $\begin{array}{l}7.83 \mathrm{e}^{-05} \\
0.001193 \\
0.001707 \\
0.003578\end{array}$ & $\begin{array}{l}\text { 'Franklin' } \\
\text { 'Yerong', } \\
\text { 'Yerong', } \\
\text { 'Franklin' }\end{array}$ & $\begin{array}{l}4.11 \\
2.92 \\
2.77 \\
2.45\end{array}$ \\
\hline NA1 & $\begin{array}{l}3398548|\mathrm{~F}| 0-66: \mathrm{T}>\mathrm{C}-66: \mathrm{T}>\mathrm{C} \\
3256942|\mathrm{~F}| 0-59: \mathrm{G}>\mathrm{A}-59: \mathrm{G}>\mathrm{A} \\
3260193|\mathrm{~F}| 0 \\
3273120|\mathrm{~F}| 0\end{array}$ & $\begin{array}{l}31.25 \\
41.64 \\
68.7 \\
47.57\end{array}$ & $\begin{array}{l}5 \mathrm{H} \\
1 \mathrm{H} \\
1 \mathrm{H} \\
5 \mathrm{H}\end{array}$ & $\begin{array}{l}19657720 \\
41172960 \\
3.75 e+08 \\
3.34 \mathrm{e}+08\end{array}$ & $\begin{array}{l}9.05 \mathrm{e}^{-05} \\
0.000148 \\
0.000165 \\
0.000266\end{array}$ & $\begin{array}{l}\text { 'Franklin' } \\
\text { 'Yerong', } \\
\text { 'Yerong', } \\
\text { 'Franklin' }\end{array}$ & $\begin{array}{l}4.04 \\
3.83 \\
3.78 \\
3.57\end{array}$ \\
\hline NA67 & $\begin{array}{l}3265037|\mathrm{~F}| 0 \\
3256942|\mathrm{~F}| 0-59: \mathrm{G}>\mathrm{A}-59: \mathrm{G}>\mathrm{A} \\
3257654|\mathrm{~F}| 0 \\
3262322|\mathrm{~F}| 0-10: \mathrm{A}>\mathrm{G}-10: \mathrm{A}>\mathrm{G} \\
3266038|\mathrm{~F}| 0\end{array}$ & $\begin{array}{l}46.81 \\
41.64 \\
31.67 \\
47.4 \\
61.51\end{array}$ & $\begin{array}{l}1 \mathrm{H} \\
1 \mathrm{H} \\
5 \mathrm{H} \\
5 \mathrm{H} \\
1 \mathrm{H}\end{array}$ & $\begin{array}{l}67025720 \\
41172960 \\
20402960 \\
3.34 \mathrm{e}+08 \\
3.61 \mathrm{e}+08\end{array}$ & $\begin{array}{l}5.15 \mathrm{E}-05 \\
5.82 \mathrm{E}-05 \\
0.000457 \\
0.000833 \\
0.000922\end{array}$ & $\begin{array}{l}\text { 'Yerong', } \\
\text { 'Yerong', } \\
\text { 'Franklin' } \\
\text { 'Franklin' } \\
\text { 'Yerong' }\end{array}$ & $\begin{array}{l}4.29 \\
4.23 \\
3.34 \\
3.08 \\
3.04\end{array}$ \\
\hline
\end{tabular}


Rpgal and Rpga2 in this study mapped to $1 \mathrm{H}$, while, previously, a major gene for near-nonhost resistance to $P$. hordeisecalini and $P$. hordei-murini in the Oregon $\times$ Wolfe population was identified (Jafary et al. 2008). Previous studies, however, also suggest there may be overlap between host and nonhost mechanisms. Trait dissection analysis performed in this and previous studies on the $\mathrm{Y} / \mathrm{F}$ population demonstrate co-location between Rpgal and QTL for APR to the barley leaf scald pathogen (Rhynchosporium secalis). The close proximity of maximum log of odds (LOD) peaks and linkage to the DArT marker $p P b-9337$ may suggest the same QTL is responsible for resistance to both pathogens. On 5HS Rpga3 maps to a similar region to Rph20, an APR gene to the barley leaf rust pathogen $P$. hordei previously mapped to 5HS (Hickey et al. 2011). While both 'Yerong' and 'Franklin' carry minor APR genes to $P$. hordei, they are negative for the closely linked marker for Rph20 (bPb-0837) (data not shown). Although it is possible that the nonfunctional APR allele to Rph20 confers resistance to the nonadapted rust species, it is likely that other genetic factors are involved. On 5HL, Rpga4 contributed by 'Franklin' maps in a similar region as the stem rust resistance gene Rpg5. $R p g 5$ was first identified in barley for conferring resistance to the rye stem rust pathogen $P$. graminis $\mathrm{f}$. sp. secali (Sun et al. 1996). A recent study characterizing resistance in Australian barley varieties to $P$. graminis f. sp. tritici determined that
'Franklin' was resistant to all $P$. graminis f. sp. tritici pathotypes tested, and further marker testing confirmed that 'Franklin' carries the functional allele of Rpg5 (Derevnina et al. 2014).

Rpgal to Rpga4 were effective in response to all P. graminis f. sp. avenae pathotypes tested in this study and may suggest the resistance is not pathotype specific. Overlapping QTL have been detected previously for multiple Puccinia species in barley but not for multiple pathotypes of $P$. graminis $\mathrm{f}$. $\mathrm{sp}$. avenae (Jafary et al. 2008). Nonpathotype-specific resistance in barley to $P$. graminis $\mathrm{f}$. sp. avenae has been reported previously, in which particular barley lines demonstrated the same phenotypic response when phenotyped with multiple $P$. graminis $\mathrm{f}$. $\mathrm{sp}$. avenae pathotypes (Martens et al. 1983). P. graminis f. sp. avenae pathotypes are differentiated based on the IT observed on oat genotypes that carry different resistance genes. The resistance response in barley to multiple pathotypes of $P$. graminis f. sp. avenae, therefore, suggests sharing of specific effectors or secreted proteins between $P$. graminis f. sp. avenae pathotypes that elicit the same resistance response in barley. All $P$. graminis f. sp. avenae pathotypes used were highly diverse, based on virulence/avirulence profiles, and the Australianderived pathotype has virulence for all known deployed resistance in oats. These findings suggest that some resistance genes in barley to $P$. graminis f. sp. avenae and, potentially,
A

Yerong $x$ Franklin $1 \mathrm{H}$

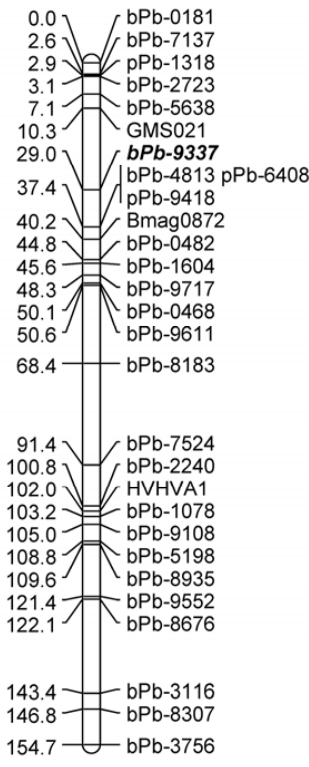

B Yerong/Franklin $1 \mathrm{H}$

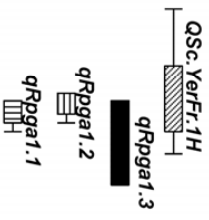

Steptoe x Morex

$1 \mathrm{H}$

\section{Consensus Barley Map}

\section{$1 \mathrm{H}$}

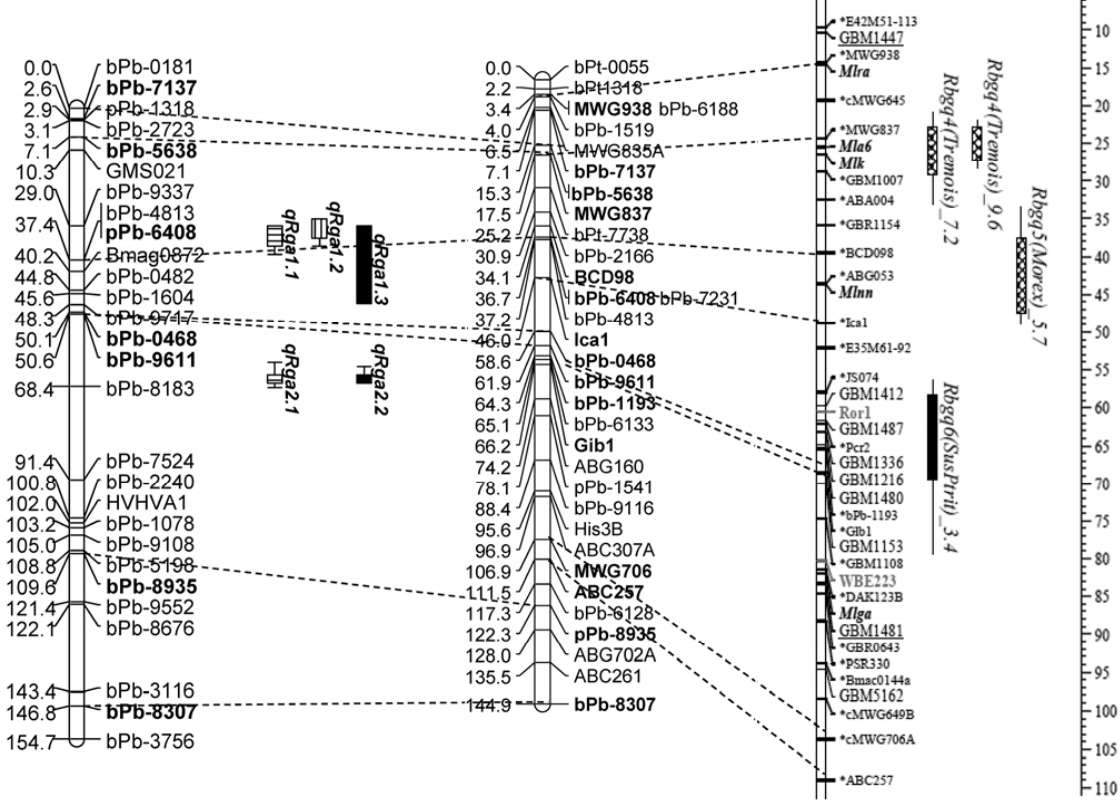

Fig. 5. Co-location of quantitative trait loci (QTL) identified for resistance to different pathotypes of Puccinia graminis f. sp. avenae in this study to previously identified QTL for A, adult plant resistance to barley leaf scald caused by Rhynchosporium secalis $($ QSc.YerFr.1H) on $1 \mathrm{HS}$ in the 'Yerong' $\times$ 'Franklin' (Y/F) doubled haploid population (Li and Zhou 2011) and $\mathbf{B}$, for resistance to powdery mildew resistance on chromosome 1H. Comparative mapping analysis between the Y/F genetic map (Xue et al. 2010; Wenzl et al. 2006), the Steptoe $\times$ Morex DArT map (Wenzl et al. 2004, 2006), and an integrated barley consensus map as described by Aghnoum and associates (2010) was performed using DArT, amplification fragment length polymorphism, and simple sequence repeat markers. The Steptoe $\times$ Morex population also contains DArT markers from a PstI/TaqI representation ('bPt' markers); however, none of these were useful for comparative analysis. Localization of QTL for resistance to barley powdery mildew caused by Blumeria graminis f. sp. hordei (Rbgq4, Rbgq5, and Rbgq6), genes for all stage resistance to powdery mildew (Mlnn, Mlk, Mla6, and Mlga), and the position of candidate genes, including Rorl, are in bold black. The locations of QTL are indicated by vertical bars at the right side of each linkage group. Solid bars represent QTL identified at the seedling stage under controlled conditions, and shaded bars represent QTL identified at the adult plant stage under field conditions. The length of QTL boxes represents approximately the log-likelihood ratio (LOD)-1 support interval and the length of QTL lines the LOD-2 support interval of the QTL based on r-multiple-QTL mapping results (Aghnoum et al. 2010). In all cases markers in common are in bold and italicized. QTL from Li and Zhou (2011) are denoted by diagonal lines and significant markers are in bold. Solid black for QTL identified using composite interval mapping in this study, horizontal and vertical striped boxes represent infection using three separate Puccinia graminis f. sp. avenae pathotypes: $41+$ $P g 9, P g 13, P g A, \mathrm{NA1}$, and NA67, respectively. 
other Puccinia species may be nonpathotype specific and differ from genes found in oat. However, only further phenotypic assessment with more $P$. graminis f. sp. avenae pathotypes will inform the potential durability of such resistance.
Histological analysis demonstrated that resistance to $P$. graminis f. sp. avenae in barley observed in this study was prehaustorial and was likely to be attributed to callose deposition and papillae formation. Previous observations of rust infection

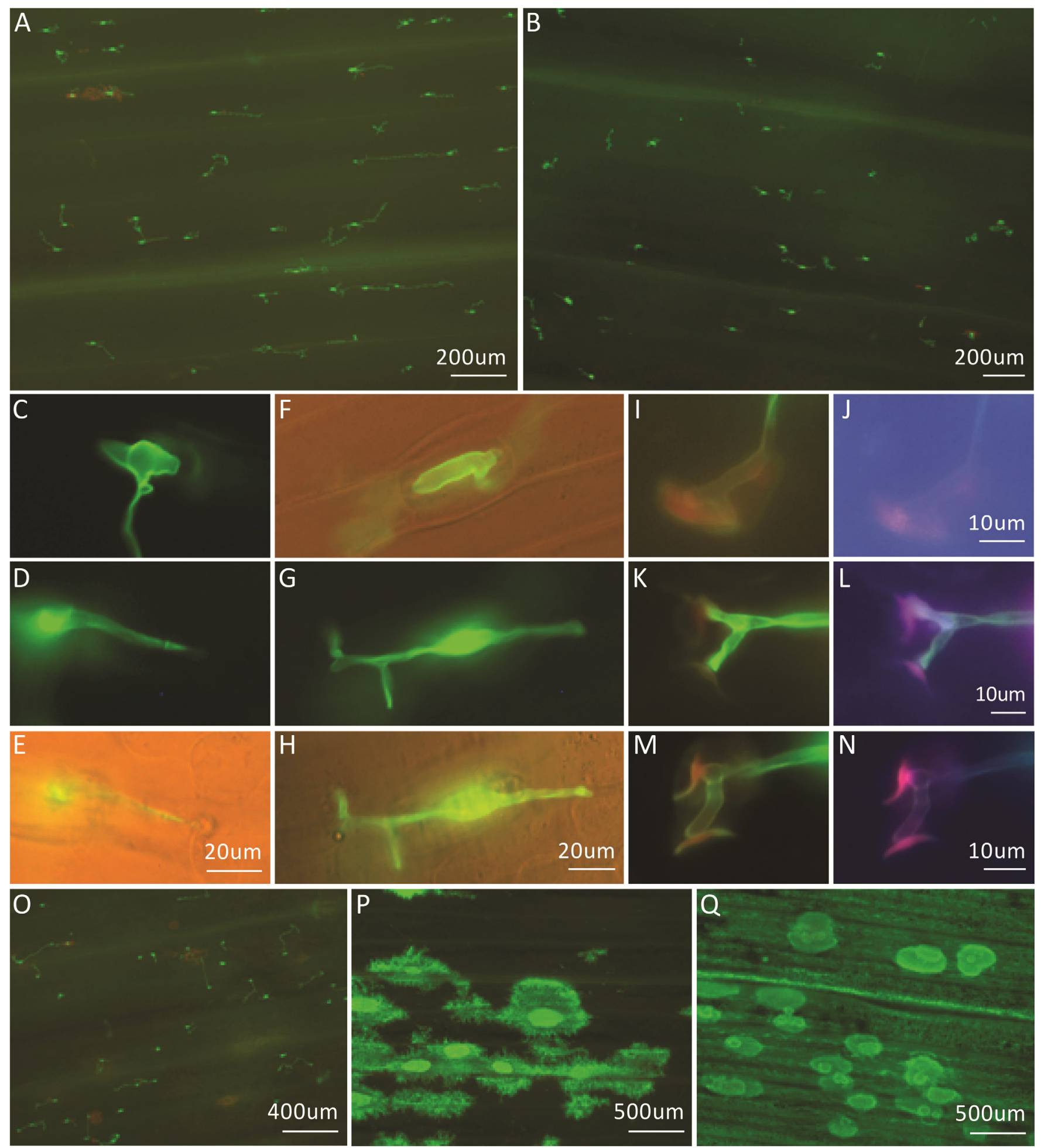

Fig. 6. A and B, Puccinia graminis f. sp. avenae infection of barley lines. C to E, P. graminis f. sp. avenae infection of 'Franklin' and 'Yerong', respectively, 10 days postinoculation (dpi). C, A typical infection site present on 'Franklin' 18 dpi, showing the appressorium, D, underlying substomatal vesicle and infection hyphae and $\mathbf{E}$, termination of this infection hyphae at the surface of a mesophyll containing a cell apposition. $\mathbf{F}$ to $\mathbf{H}$, A $P$. graminis f. sp. avenae infection site on 'Yerong' consisting of $\mathbf{F}$, an appressorium and $\mathbf{G}$ and $\mathbf{H}$, an underlying substomatal vesicle with several infection hyphae that do not successfully penetrate plant cell walls. I and $\mathbf{J}$, Autofluorescent cell-wall appositions associated with cell-wall contact of $P$. graminis $\mathrm{f}$. sp. avenae infection hyphae 10 dpi on 'Franklin', $\mathbf{K}$ and $\mathbf{L}$, 'Yerong' and $\mathbf{M}$ and N, YF41. Panels J, L, and $\mathbf{N}$ were photographed under UV light. $\mathbf{O}$ to $\mathbf{Q}$, P. graminis f. sp. avenae growth on lines YF41, YF318, and a fully susceptible oat cultivar, Swan, 10 dpi. In all panels, leaf material was stained with wheat germ agglutinin conjugated to the fluorophore fluorescein isothiocyanate and was examined under blue light unless stated otherwise. 
structures in different rice varieties, in all cases, show haustorial formation and variable hyphal colonies (Ayliffe et al. 2011). A recent study demonstrated that increased reactive oxygen species were responsible for resistance to $P$. striiformis f. sp. tritici among different subspecies of rice (japonica and indica) (Yang et al. 2013). This suggests that resistance in barley to $P$. graminis f. sp. avenae, in this case, is likely to be different from the nonhost resistance mechanisms observed in rice. Callose production in $B$. distachyon was reported with various rust species, similar to that of the wheat basal defense response (Ayliffe et al. 2013). Comparative genomic analysis indicates that Rpga2 may co-locate to previously mapped QTL overlapping the Rorl locus (Acevedo-Garcia et al. 2014; Aghnoum et al. 2010). Previous studies have found that Rorl is required for $m l o$-derived callose deposition resistance in barley to Blumeria graminis f. sp. hordei. It is possible that Rpga2 is contributing to the callose deposition observed in this study. Of further interest is the apparent co-location of Rpgal with previously identified genes for Blumeria graminis f. sp. hordei resistance (Mlnn, Mla6, and $M l k$ ) observed in this study. given the recent cloning of wheat stem rust resistance gene $S r 33$ that was found to be a homologue of Mla in barley (Periyannan et al. 2013).

In summary, the presence of transgressive segregation in the Y/F population demonstrates that prehaustorial resistance to multiple pathotypes of $P$. graminis f. sp. avenae is simply inherited. Resistance to $P$. graminis $\mathrm{f}$. $\mathrm{sp}$. avenae identified in the Y/F DH population was effective against all pathotypes tested. Comparative mapping analysis suggests there may be overlap between resistance mechanisms to both nonadapted and adapted pathogens. The resistance genes identified in this study could be further applied for crop improvement based on transgenic approaches in target crop species.

\section{MATERIALS AND METHODS}

\section{Plant materials.}

A DH population of 177 lines derived from a cross between 'Yerong' (Australian six-rowed feed barley) and 'Franklin' (Australian two-rowed malting barley) was used for genetic analysis of resistance to $P$. graminis f. sp. avenae in this study. Genomic DNA was extracted from all DH lines and the parental genotypes using the CTAB method essentially as described by Fulton and associates (1995). A total of 93 of these DH lines were sent for DArTseq genotypic analysis for MTA analysis.

\section{Phenotypic analysis of resistance \\ to Puccinia graminis f. sp. avenae.}

Seedlings were grown in plastic pots (90 mm diameter) containing a potting mix comprising composted pine bark and coarse sand in a ratio of $4: 1$. Pots were fertilized with the soluble nitrogenous fertilizer Aquasol (Hortico Pty Ltd, Australia) at the rate of $30 \mathrm{~g}$ in 10 liters of water for 200 pots prior to sowing. Differential lines were sown as clumps (four lines per pot) of approximately 10 seeds each. Postinoculation, the seedlings were fertilized with Aquasol/ammonium nitrate (1:1) at a rate of $25 \mathrm{~g}$ in 10 liters of water per 100 pots. Plants were maintained both before and after inoculation in a temperaturecontrolled greenhouse $\left(16\right.$ to $\left.25^{\circ} \mathrm{C}\right)$ under natural lighting. Assessment of resistance to $P$. graminis $\mathrm{f}$. sp. avenae was performed at the seedling stage, using three different pathotypes: $41+P g$ 9, $P g 13, P g A$ from Australia (virulent on all known $P$. graminis f. sp. avenae resistance genes); NA1 (race BLD) with virulence/avirulence formula $6,15 / 1,2,3,4,8,9,10,12,13,16$ from Winnipeg, Canada; and NA67 (race TJJ) with virulence/ avirulence formula $1,2,3,4,8,9,13,15 / 6,10,12,16$ from Manitoba, Canada (Table 1).

\section{Inoculation procedures.}

Inoculations were performed on 10-day-old seedlings. Urediniospores were suspended in approximately $5 \mathrm{ml}$ of light mineral oil (Isopar L) and were sprayed with a mist atomizer over the top of the seedlings. To prevent contamination, the spray equipment was washed in $70 \%$ ethanol and was rinsed in running tap water between successive inoculations. Seedlings inoculated with $P$. graminis $\mathrm{f}$. sp. avenae were incubated for approximately $48 \mathrm{~h}$ over trays of water covered by sealed polythene hoods under which sufficient dew (humidity) was generated. Incubation enabled the urediniospores to germinate and allowed rust infection to take place. After incubation, the plants were moved to greenhouse microclimate rooms in which temperatures were kept at optimum conditions for rust development.

\section{Disease assessment.}

Disease response was assessed 12 days after inoculation, using a modified 0 to 4 scale as described by McIntosh and associates (1995). Variations of the IT were indicated by the use of '-' (less than average for the class), '+' (more than average for the class), ';' (flecking), 'C' (chlorosis), 'N' (necrosis), and ' $\mathrm{X}$ ', which denotes a mesothetic infection type, with a mixture of infection types on the same leaf. A comma separating different infection types was used to indicate heterogeneity within a given test host genotype. When two different infection types were observed on a single leaf, they were written together without a comma. The phenotypic data for the $\mathrm{Y} / \mathrm{F}$ population were classified using both binary (presence and absence of the 0; indicating IT) and quantitative measurements ( 0 immune to 4 susceptible scale based on the severity of IT).

\section{QTL analysis for resistance}

to $P$. graminis $\mathrm{f}$. sp. avenae in Y/F DH population.

QTL analysis was performed on $177 \mathrm{Y} / \mathrm{F}$ DH lines based on a previously published genetic map build (Xue et al. 2010). Subsets of marker loci were selected to provide even coverage of the genome with marker intervals of approximately $3 \mathrm{cM}$. SMR was used initially to identify significant associations with selected genetic markers. CIM methods were used to identify and confirm the presence of QTL using QTL Cartographer 2.5 software (Basten et al. 1994). The maximum LOD score of association between the genotype and trait data was calculated for CIM, and QTL location predictions were accepted for CIM for values greater than a threshold value of 2.5. Permutation analysis (1,000 iterations) was used to establish an experiment-wise significance value at the 0.05 confidence level, defined as a minimum LOD threshold for each trait in CIM (Churchill and Deorge 1994; Doerge and Churchill 1996). For CIM analysis, the maximum LOD value, proportion of phenotypic variance attributable to the QTL, and the extent of drops by 1 and 2 LOD units from the maximum value on the genetic map were tabulated.

\section{DArTseq genotypic analysis in the $\mathrm{Y} / \mathrm{F}$ population.}

Genomic DNA was extracted from the leaf tissues of a single plant from a subset of 93 from the 177 original Y/F DH lines, using CTAB essentially as described by Fulton and associates (1995). This DNA of each DH line was diluted to 100 ng per microliter and was subjected to genotypic analysis using the DArTseq platform, and markers were subsequently curated essentially as described by Courtois and associates (2013), except that the physical and centiMorgan positions of all DArTseq markers were determined based on the Hordeum vulgare L. cv. Bowman genome assembly and consensus map, respectively (Mayer et al. 2012). 
MTA analysis using DArTseq on the Y/F DH population.

Associations between DArT marker genotypes and resistance to each $P$. graminis $\mathrm{f}$. sp. avenae pathotype were tested using Fisher's exact test on a $2 \times 2$-count table using R statistical software. The means of the three different pathotype scores for two marker genotypes $(1,0)$ were compared by conducting the two sample Student's $t$-test. The null hypothesis was that the DArT marker genotypes were not associated with resistance to $P$. graminis f. sp. avenae. Hence, a random distribution of genotypes in the resistant and susceptible phenotypic groups. The $-\log 10$ of $P$ values were plotted against the positions on the physical Bowman genome assembly (Mayer et al. 2012) by means of chromosome-wise and genome-wide (Manhattan) plots.

\section{Histological characterization of resistance.}

Infection structures of $P$. graminis f. sp. avenae were visualized on barley as described by Ayliffe and associates (2011). Briefly, leaf tissue was cleared by autoclaving in a $1 \mathrm{M} \mathrm{KOH}$ solution, and neutralized tissue samples then stained with wheat germ agglutinin conjugated to the fluorophore fluorescein isothiocyanate (WGA-FITC), which binds to chitin. All WGA-FITC-stained tissue was examined under blue light excitation.

\section{ACKNOWLEDGMENTS}

This research was supported by the Australian Research Council. The authors thank M. Williams for technical support.

\section{LITERATURE CITED}

Acevedo-Garcia, J., Collins, N., Ahmadinejad, N., Ma, L., Houben, A., Bednarek, P., Benjdia, M., Freialdenhoven, A., Altmüller, J., Nürnberg, P., Reinhardt, R., Schulze-Lefert, P., and Panstruga, R. 2013. Fine mapping and chromosome walking towards the Rorl locus in barley (Hordeum vulgare L.). Theor. Appl. Genet. 126:2969-2982.

Aghnoum, R., Marcel, T. C., Johrden, A., Pecchioni, N., Schweizer, P., and Niks, R. 2010. Basal host resistance of barley to powdery mildew: Connecting quantitative trait loci and candidate genes. Mol. Plant-Microbe Interact. 23:91-102.

Allen, E., Blenis, P., and Hiratsuka, Y. 1990. Histological evidence of resistance to Endocronartium harknessii in Pinus contorta var. latifolia. Can. J. Bot. 68:1728-1737.

Ayliffe, M. A., Jin, Y., Kang, Z., Persson, M., Steffenson, B., Wang, S., and Leung, H. 2011. Determining the basis of nonhost resistance in rice to cereal rusts. Euphytica 179:33-40.

Ayliffe, M., Singh, D., Park, R., Moscou, M., and Pryor, T. 2013. Infection of Brachypodium distachyon with selected grass rust pathogens. Mol. Plant-Microbe Interact. 26:946-957.

Bartos, P., Fleischmann, G., Samborski, D. J., and Shipton, W. A. 1969. Studies on asexual variation in the virulence of oat crown rust, Puccinia coronata f. sp. avenae, and wheat leaf rust, Puccinia recondita. Can. J. Bot. 47:1383-1387.

Basten, C. J., Weir, B. S., and Zeng, Z. 1994. Zmap-a QTL cartographer. Pages 65-66 in: Proceedings of the 5th World Congress on Genetics Applied to Livestock Production: Computing Strategies and Software, Volume 22. C. Smith, J. S. Gavora, B. B. J. Chesnais, W. Fairfull, J. P. Gibson, B. W. Kennedy, and E. B. Burnside, eds. Department of Animal \& Poultry Science, University of Guelph, Ontario, Canada.

Churchill, G., and Doerge, R. 1994. Empirical threshold values for quantitative trait mapping. Genetics 138:963-971.

Collins, N., Niks, R., and Schulze-Lefert, P. 2007. Resistance to cereal rusts at the plant cell wall-what can we learn from other host-pathogen systems? Aust. J. Agric. Res. 58:476-489.

Courtois, B., Audebert, A., Dardou, A., Roques, S., Ghneim-Herrera, T., Droc, G., Frouin, J., Rouan, L., Goze, E., Killian, A., Ahmadi, N., and Dingkuhn. M. 2013. Genome-wide association mapping of root traits in a Japonica rice panel PLOS One 8:e78037. Published online.

Dangl, J., and Jones, J, 2006. The plant immune system. Nature 444:323329.

Derevnina, L., Fetch, T., Singh, D., Brueggeman, R., Dong, C., Park, R. F. 2014. Analysis of stem rust resistance in Australian barley cultivars Plant Dis. http://dx.doi.org/10.1094/PDIS-11-13-1174-RE. Published online.

Doerge, R., and Churchill, G. 1996. Permutation tests for multiple loci affecting a quantitative character. Genetics 142:285-294.

Fan, J., and Doerner, P. 2012. Genetic and molecular basis of nonhost disease resistance: Complex, yes; silver bullet., no. Curr. Opin. Plant Biol. 4:15400-15406.

Figueroa, M., Alderman, S., Garvin, D., and Pfender, W. 2013. Infection of Brachypodium distachyon by formae speciales of Puccinia graminis: Early infection events and host pathogen incompatibility. PLoS ONE 8:e56857. Published onine.

Fulton, T, Chunwongse, J., and Tanksley, D. 1995. Microprep protocol for extraction of DNA from tomato and other herbaceous plants. Plant Mol. Biol. Rep. 13:207-209.

Grambow, H. 1977. The influence of volatile leaf constituents on the in vitro differentiation and growth of Puccinia graminis f. sp. tritici. $\mathrm{Z}$. Pflanzenphysiol. 85:361-372.

Green, G. 1971. Hybridisation between Puccinia graminis tritici and Puccinia graminis secali and its evolutionary implications. Can. J. Bot. 49:2089-2095.

Grove, W. 1913. The British rust fungi (Uredinales). Pages 64-67. University Press, Cambridge.

Hickey, L. T., Lawson, W., Platz, G. P., Dieters, M., Arief, V. N., German, S., Fletcher, D., Park, R. F., Singh, D., Pereyra, S., and Franckowiak, J. 2011. Mapping Rph20: A gene conferring adult plant resistance to Puccinia hordei in barley. Theor. Appl. Genet. 123:55-68.

Hovmøller, M., Justesen, A., and Brown, J. 2002. Clonality and long-distance migration of Puccinia striiformis f. sp. tritici in north-west Europe. Plant Pathol. 51:24-32.

Hukelhoven, R. 2007. Cell wall associated mechanisms of disease resistance and susceptibility. Ann. Rev. Phytopathol. 45:101-127.

Jaccoud, D., Peng, K., Feinstein, D., and Kilian, A. 2001. Diversity arrays: A solid state technology for sequence information independent genotyping. Nucleic Acids Res. 29:E25.

Jafary, H., Albertazzi, G., Marcel, C., and Niks, R. 2008. High diversity of genes for non-host resistance of barley to heterologous rust fungi. Genetics 78:2327-2339.

Li, H. B., and Zhou, M. X. 2011. Quantitative trait loci controlling barley powdery mildew and scald resistances in two different barley doubled haploid populations Mol. Breeding 27:479-490.

Martens, J., Green, G., and Buchannon, K. 1983. Inheritance of resistance to Puccinia graminis $\mathrm{f}$. sp. avenae in a Hordeum vulgare selection Can. J. Plant Pathol. 5:266-268.

Mayer K. F., Waugh R., Brown J. W., Schulman A., Langridge P., Platzer M., Fincher G. B., Muehlbauer G. J., Sato K., Close T. J., Wise R. P., and Stein, N. 2012. A physical, genetic and functional sequence assembly of the barley genome. Nature 491:711-716.

McIntosh, R., Wellings, C., and Park, R. 1995. Wheat rusts: An atlas of resistance genes. CSIRO Publishing, Melbourne, Australia.

Niks, R., and Marcel, T. 2009. Nonhost and basal resistance: How to explain specificity? New Phytol. 182:817-828.

Niu, Z., Puri, K. D., Chao, S., Jin, Y., Sun, Y., Steffenson, B., Shivcharan, S., Maan, S., Xu, S., and Zhong, S. 2013. Genetic analysis and molecular mapping of crown rust resistance in common wheat. Theoret. Appl. Genet. 127:609-19.

Pahalawatta, V., and Chen, X. 2005. Genetic analysis and molecular mapping of wheat genes conferring resistance to the wheat stripe rust and barley stripe rust pathogens. Phytopathology 95:427-432.

Park, R. F., Burdon, J. J., and Jahoor, A. 1999. Evidence for somatic hybridisation in nature in Puccinia triticina, the leaf rust pathogen of wheat. Mycol. Res. 103:715-723.

Periyannan, S., Moore, M., Ayliffe, M., Bansal, U., Wang, X., Huang, L., Deal, K., Luo, M., Kong. X., Bariana, H., Mago, R., McIntosh, R., Dodds, P., Dvorak, J., and Lagudah, E, 2013. The gene Sr33, an orthologue of barley Mla genes, encodes resistance to wheat stem rust race $U g 99$. Science 241:786-788.

Pretorius, Z., Singh, R., Wagoire, W., and Payne, T. 2000. Detection of virulence to wheat stem rust resistance gene $S r 31$ in Puccinia graminis f. sp. tritici in Uganda. Plant Dis. 84:203.

Rodrigues, P., Garrood, J., Shen, Q., Smith, P., and Boyd, L. 2004. The genetics of non-host disease resistance in wheat to barley yellow rust. Theor. Appl. Genet. 109:425-432.

Schulze-Lefert, P., and Panstruga, R. 2011. A molecular evolutionary concept connecting non-host resistance, pathogen host range, and pathogen speciation. Trends Plant Sci. 3:117-125.

Singh, R., Hodson, D., Huerta-Espino, J., Jin, Y., Njau, P., Wanyera, R., Herrera-Foessel, S., and Ward, W. 2008. Will stem rust destroy the worlds wheat crop? Adv. Agron. 98:71-80.

Sui, X., He, Z., Lu, Y., Wang, Z., and Xia, X. 2010 Molecular mapping of a non-host resistance gene YrpstY1 in barley (Hordeum vulgare L.) for resistance to wheat stripe rust. Hereditas 147:176-182. 
Sun, Y., Steffenson, B. J., and Jin, Y. 1996 Genetics of resistance to Puccinia graminis $\mathrm{f}$ sp secalis in barley line Q21861. Phytopathology 86:1299-1302.

Watson, I. 1970. Changes in virulence and population shifts in plant pathogens. Ann. Rev. Phytopathol. 8:209-230.

Watson, I., and de Sousa, C. 1982. Long distance transport of spores of Puccinia graminis tritici in the southern hemisphere. Proc. Linnean Soc. NSW 106:311-321.

Wellings, C., and McIntosh, R. 1990. Puccinia striiformis f. sp. tritici in Australasia: Pathogenic change during the first ten years. Plant Pathol. 39:316-325.

Wellings, C., McIntosh, R., and Walker, J. 1987 Puccinia striiformis f. sp. tritici in Australia-Possible means of entry and implications for plant quarantine. Plant Pathol. 36:239-241.

Wenzl, P., Carling, J., Kudrna, D., Jaccoud, D., Huttner, E., Kleinhofs, A., and Kilian, A. 2004. Diversity arrays technology (DArT) for wholegenome profiling of barley. Proc. Natl. Acad. Sci. U.S.A. 101:9915-9920.
Wenzl, P., Li, H., Carling, J., Zhou, M., Raman, H., Paul, E., Hearnden, P., Maier, C., Xia, L., and Caig, V. 2006. A high-density consensus map of barley linking DArT markers to SSR, RFLP and STS loci and agricultural traits. BMC Genomics 7:206. Published online.

Xue, D., Zhou, M., Zhang, X., Chen, S., We, K., Zeng, F., Ying, M., Wu, F., and Zhang, G. 2010. Identification of QTLs for yield and yield components of barley under different growth conditions Journal of Zhejiang University-SCIENCE B Biomed. Biotechnol. 169-176.

Yang, Y., Zhao, J., Xing, H., Wang, J., Zhou, K., Zhan, G., Zhang, H., Kang, Z. 2013. Different non-host resistance responses of two rice subspecies, japonica and indica, to Puccinia striiformis f. sp. tritici. Plant Cell Rep. 33:423-433.

\section{AUTHOR-RECOMENDED INTERNET RESOURCE}

R statistical software: www.r-project.org 